\title{
A CONSTITUIÇÃO DO GRUPO DE ESTUDOS SOBRE POLÍTICAS E GESTÃO EDUCACIONAL E OS PERCALÇOS DOS PROCESSOS DEMOCRÁTICOS NO MUNICÍPIO DE JEQUIÉ, NA BAHIA
}

\author{
Ubirajara Couto Lima ${ }^{1}$ \\ Geisa Pereira Gomes ${ }^{2}$ \\ Larissa Monique de Souza Almeida ${ }^{3}$ \\ Thiana do Eirado Sena de Souza ${ }^{4}$
}

\section{RESUMO}

Esse trabalho relata as ações de pesquisa/extensão desenvolvidas pelo Grupo de Estudos sobre Políticas e Gestão Educacional (GEPGE), cuja finalidade mais ampla é compreender o processo de intervenção do Estado nas políticas educacionais e na gestão da escola pública. Para tanto, foram realizadas discussões teóricas e pesquisa qualitativa em duas escolas públicas de Jequié, culminando numa mesa redonda para a socialização dos resultados, os quais evidenciaram os entraves para a efetivação do projeto democrático consubstanciados em práticas de cunho tradicional identificadas nas escolas.

Palavras-chave: Escola pública. Gestão democrática. Políticas educacionais.

\footnotetext{
${ }^{1}$ Professor Assistente da UESB, pesquisador do Grupo de Estudos e Pesquisa Ideologias e Lutas de Classe (GEILC)/CNPq) e coordenador do GEPGE. E-mail: bira.lima@hotmail.com

${ }^{2}$ Graduanda do curso de Pedagogia/UESB, membro do GEILC/CNPq e do GEPGE. E-mail: geipergom@hotmail.com

${ }_{3}^{3}$ Graduanda do curso de Pedagogia/UESB, membro do GEILC/CNPq e do GEPGE. E-mail: larymonik2@hotmail.com

${ }^{4}$ Graduanda do curso de Pedagogia/UESB, membro do GEILC/CNPq e do GEPGE. E-mail: thysena@hotmail.com
}

\begin{tabular}{l|l|l|l|l}
\hline Revista Extensão \& Cidadania & Vitória da Conquista & v. 1, n. 2 & p. 71-83 & jul/dez. 2013 \\
\hline
\end{tabular}




\title{
THE CONSTITUTION OF THE STUDY GROUP ON EDUCATIONAL POLICY AND MANAGEMENT AND OBSTACLES OF DEMOCRATIC PROCESSES IN JEQUIÉ COUNTY, IN BAHIA
}

\begin{abstract}
This paper describes the actions of research/extension developed by the Study Group on Educational Policy and Management (GEPGE), whose broader purpose is to understand the process of state intervention in education policy and management of public schools. To this end, discussions were held theoretical and qualitative research in two public schools in Jequié, culminating in a round table for the socialization of the results, which showed the obstacles to the realization of the democratic project embodied in practices of traditional features identified in schools.
\end{abstract}

Keywords: Democratic management. Educacional policies. Public school.

\section{Introdução}

O presente trabalho relata a experiência do Grupo de Estudos sobre Políticas e Gestão Educacional (GEPGE), vinculado a Universidade Estadual do Sudoeste da Bahia (UESB), no ano de 2010. As ações desenvolvidas, no grupo, fomentam os processos de pesquisa e extensão e buscam a compreensão do processo de intervenção do Estado nas políticas educacionais brasileiras e na gestão da escola pública, visto que nos últimos anos, as lutas em torno da educação tem se voltado à garantia de processos democráticos na escola.

Durante o período supracitado, realizamos diversas discussões que circunscrevem a proposta de estudo/ação do GEPGE, bem como o desenvolvimento de atividades que ultrapassaram os muros da academia e envolveram a comunidade local. Inicialmente, tratamos da relevância dos Conselhos Escolares como mecanismos basilares para o processo de democratização da escola, enfatizando a amplitude de sua atuação no ambiente escolar.

No primeiro semestre, cadastramos institucionalmente, um projeto de extensão, sob a coordenação da professora Daniele Farias 
Freire Raic, intitulado "Ressignificação: o conselho escolar na busca pela qualidade da educação", visando contribuir com a implantação dos conselhos escolaresem duas instituições de ensino no município de Jequié, Bahia, sendo uma escola municipal e outra estadual, através de grupos de estudos, reflexões frente ao papel dos conselhos e ressignificação da atuação dosmesmos nas escolas envolvidas.

O projeto estruturou-se em encontros mensais e contou com a participação dos conselheiros da unidade escolar - in loco - e a realização de uma mesa redonda para debatermos os resultados das ações desenvolvidas envolto da comunidade tanto acadêmica como local. Devemos ressaltar que constava como culminância do referido projeto, a criação e consolidação de um Fórum Permanente de Educação, com o propósito de discutir, avaliar e propor políticas para a gestão democrática da educação. Infelizmente, por questões estruturais, essa ação não foi concretizada, o que deve ocorrer em breve.

Oportunamente, informamos que esse relato está organizado em três tópicos, os quais abordam, inicialmente, o princípio da gestão escolar com base na Constituição Federal, de 1988, e na Lei de Diretrizes e Bases da Educação Nacional, no 9394/96, enfatizando a perspectiva democrática participativa em direção à melhoria da qualidade da educação pública. Em seguida, o percurso histórico do Grupo de Estudos sobre Políticas e Gestão Educacional e suas atividades desenvolvidas desde a sua criação até o final do ano de 2010. E finalmente, a descrição do processo de investigação realizadas nas escolas e dos resultados obtidos.

\section{Os novos rumos da educação brasileira: a gestão democrática como garantia efetiva da cidadania}

A dupla face da descentralização, a política e a econômica, deixase evidenciar como uma clara contraposição de projetos antagônicos no seio da sociedade brasileira. De um lado, no contexto da luta pelo fim da ditadura militar, período caracterizado pela montagem de mecanismos de poder fortemente centralizado, novos sujeitos sociais, 
que por iniciativa da sociedade civil ganham visibilidade na arena pública, por meio da luta de diversos movimentos sociais, de entidades sindicais diversas e de sujeitos oriundos das periferias dos grandes centros urbanos. De outro lado, enquanto a sociedade civil envidava esforços no sentido de conquistar, universalizar e consolidar direitos sociais, o Estado brasileiro, afinado com as mudanças de ordem econômica que ocorriam nos países do centro do capitalismo, de onde emergiu o modelo neoliberal, definido por Menezes (2001, p. 59) como "o receituário econômico e político, de caráter conservador, resultante da crítica ao Estado de Bem-Estar Social”, adota as imposições do capital internacional, então sob o comando dos órgãos multilaterais e começa a implementar um processo que vai na contra-mão dos desejos democráticos da sociedade civil.

Nos últimos trinta anos, a sociedade civil brasileira, a partir de novas práticas político-culturais, tem buscado modificar as nossas raízes históricas de não-cidadania na formação do Estado e da própria sociedade, bem como dirimir as profundas desigualdades sociais que excluem boa parte da população dos benefícios do desenvolvimento e da modernização em curso no país.

Nesse sentido, compreende-se que o nosso histórico autoritarismo advém da inexistência de uma esfera pública democrática - como espaço de produção de consentimento e regulação de conflitos sociais -, assim como pela ausência de mediações institucionais e sociais e de um sistema político que funcionasse como representação de interesses.

De forma incontestável, a promulgação da Constituição Federal de 1988 representou um marco na trajetória de luta por direitos civis, políticos e sociais. Conhecida também como a Constituição Cidadã, ela estabeleceu a universalização de vários direitos, a destacar a educação e a saúde, bem como determinou uma inédita configuração federativa, consubstanciada pela descentralização político-administrativa, a desconcentração dos recursos com partilha mais equânime da arrecadação em favor dos Estados e municípios e, algo primordial: a participação da comunidade na gestão das políticas públicas (LIMA, 2009). 
Com a Constituição Federal de 1988 e a posterior regulamentação da Lei de Diretrizes e Bases da Educação Nacional, no 9394/96, o princípio da gestão democrática da educação assume um novo caráter e, consequentemente, traz novas exigências para todos os envolvidos. Estabelece a participação de toda comunidade escolar nos processos decisórios da instituição, como na gestão da escola, na escolha direta dos diretores, na votação e eleição dos integrantes dos Conselhos Escolares e na construção de forma colaborativa do Projeto Político Pedagógico da escola.

Outrossim, devemos pensar no conceito de participação não só restringindo-se às tomadas de decisões, mas também na execução de atividades. Esse tema deve ser compreendido como uma relação mútua entre comunidade e escola, a fim de promover um benefício social e educacional para todos os envolvidos na comunidade escolar (PARO, 1995).

A política de gestão democrática da educação pressupõe um novo modo de administração escolar promovendo a construção coletiva da cidadania ao mesmo tempo em que garante aos indivíduos o conhecimento acerca dos seus direitos e deveres, favorecendo para a formação de uma visão política e democrática da realidade educacional e social. Para Libâneo (2001, p. 81),

[...] na escola deve-se está presente a participação de professores, pais, alunos, funcionários e outros representantes da comunidade, bem como uma participação interativa comunicativa, uma abertura clara para discussões de problemas, buscando sempre o consenso através do diálogo.

As práticas ligadas à participação cidadã objetiva trazer a esfera de tomada de decisões para o nível local, sendo concebidas como forma de intervenção social periódica e planejada - que abrange todo o processo de formulação e implementação de políticas públicas -, institucionalizando-se a partir de estruturas criadas no aparato governamental (a exemplo dos conselhos gestores), compostas 
por representantes eleitos diretamente pela sociedade de onde eles provêm, já que a participação cidadã prescinde da institucionalização de canais para que haja o debate em torno dos interesses coletivos (GOHN, 2007).

O aumento da participação de educadores, pais e funcionários na gestão escolar se dão, principalmente, pela formação/organização dos Conselhos Escolares que exercem uma função mediadora entre Estado e sociedade, preconizando a continuidade das políticas educacionais que atualmente buscam promover a participação social no cenário educacional do país.

As ações desempenhadas pelo Conselho referem-se a medidas que visem a superação das atuais práticas escolares, as quais expressariam os condicionantes ideológicos, institucionais, políticosociais e materiais da participação da comunidade na gestão escolar (PARO, 1995). Assim, esse deve atuar com função deliberativa (o poder de decisão sobre determinadas questões), função consultiva (medidas que visem o aperfeiçoamento de ensino), função fiscal (fiscalização das verbas escolares, do cumprimento das normas institucionais) e função mobilizadora (incentivar a comunidade a participar das decisões da escola para uma melhor qualidade do ensino) promovendo transformações justas e igualitárias no cotidiano escolar.

Por conseguinte, os Conselhos Escolares apresentam-se como espaços públicos privilegiados, nos quais, tensões e conflitos a respeito de questões educacionais podem surgir, superando práticas monolíticas ou pretensamente harmoniosas, ao tempo que se configuram como espaços institucionais de articulação de soluções locais para os problemas do cotidiano escolar (CAMARGO; ADRIÃO, 2003).

\section{O grupo de estudos sobre políticas e gestão educacional como espaço de discussão, produção e socialização do conhecimento}

O desafio da universidade é, ao situar-se no contexto da sociedade, buscar transformar o conhecimento em um instrumento que rompa com a segregação social de modo a promover uma sociedade 
crítica, reflexiva e participativa. Ao passo que essa se caracteriza como produtora, transmissora e socializadora de conhecimentos.

Sabemos que a universidade tem como função precípua a indissociabilidade entre o ensino, a pesquisa e a extensão. Considerando que a discussão frente à gestão democrática da educação tem ganhado grande visibilidade nos últimos anos, é fundamental um trabalho consistente de amplo debate nesse sentido, a fim de compreender e contribuir com sua efetivação na educação.

A proposta de criar um Grupo de Estudos voltado para a temática das políticas e gestão educacional surge da necessidade de ampliar essas discussões para além da sala de aula. Desse modo, o Grupo de Estudos sobre Políticas e Gestão Educacional (GEPGE) inicia suas atividades em setembro de 2009, no Laboratório de Educação, da Universidade Estadual do Sudoeste da Bahia, campus de Jequié, sob a coordenação do professor mestre Ubirajara Couto Lima, tendo como integrantes nove alunos do curso de Pedagogia. Salientamos que o Grupo de Estudos está vinculado à Linha de Pesquisa "Educação e Movimentos Sociais", do Grupo de Pesquisa do Museu Pedagógico (GEILC).

O GEPGE tem como objetivos fundamentais estudar/ compreender/vivenciar as temáticas das políticas públicas e da gestão da educação, como também fortalecer a tríade estudo-pesquisa-extensão. A proposta fundamenta-se em atividades interligadas, apoiadas numa metodologia histórico-crítica, contando com a participação dos membros envolvidos (da universidade e comunidade externa). As ações realizadas ainda preconizam a organização de eventos com a participação da comunidade acadêmica e da comunidade local, favorecendo o diálogo, a troca e valorização das diferentes formas de saber e a consequente melhoria do entorno político-social e educativo.

As primeiras reuniões foram primordiais para a consolidação do GEPGE, sendo definidas as Linhas de Estudos (Estado, Educação e Sociedade Civil; Gestão e Financiamento da Educação; e Democratização da Escola) e o cronograma de encontros semanais. A elaboração do quadro de atividades para 2010 foi acompanhada e 
discutida por todos os membros, os quais sugeriram como pressuposto inicial dos trabalhos, os estudos acerca da implantação dos Conselhos Escolares na rede pública de ensino. Naquela oportunidade, ficou decidido que os cadernos elaborados pelo Programa Nacional de Fortalecimentos dos Conselhos Escolares (BRASIL, 2004) seriam apresentados e debatidos pelos membros do Grupo. Os cadernos abordam diversas temáticas fundamentais para dar sustentabilidade e viabilização ao funcionamento dos Conselhos Escolares e ao próprio significado do Programa, em seus objetivos, limites e possibilidades. Dentre as temáticas, destacamos: os direitos humanos; o tempo pedagógico; financiamento da educação; aprendizagem do aluno; democratização da escola e construção da cidadania.

Após a conclusão do processo de estudos e debates dos referidos cadernos, o Grupo inicia um trabalho de desenvolvimento do projeto de extensão "Ressignificação: o conselho escolar na busca pela qualidade da educação", visando contribuir com o fortalecimento dos Conselhos de duas unidades escolares no município de Jequié, Bahia, sendo uma escola municipal e outra estadual. Através de grupos de estudos, foram propostas reflexões acerca do papel dos conselhos escolares e da ressignificação da atuação desses nas escolas envolvidas.

Em meados do segundo semestre de 2010, o GEPGE realizou sua primeira mesa redonda tendo como meta discutir os resultados do projeto de extensão referido. Para tanto, firmou parcerias com outros professores da instituição que também propuseram temáticas como, políticas, desenvolvimento social, cidadania, Conselhos Escolares, os novos rumos da educação brasileira (CONAE e PNE), para serem debatidos nesse evento.

Considerando que, na Universidade Estadual do Sudoeste da Bahia (UESB), campus de Jequié, há diversos cursos de licenciatura, o evento permitiu estreitar os laços com as diversas áreas do conhecimento, favorecendo o diálogo, a troca de saberes, assim como possibilitou a socialização de conhecimentos e experiências, incentivando os participantes a compreenderem a natureza democrática, para a 
melhoria do cenário educacional em detrimento de práticas sociais próprias da cultura política tradicional.

\section{O grupo de estudos no interior da escola}

Compreender os desafios e as implicações para a implantação dos Conselhos Escolares é fundamental para entender o ambiente escolar, enfatizando-o como espaço educativo, participativo e de formação crítica do sujeito. Nessa perspectiva, o Conselho estabelece relações institucionais de representação frente ao poder e à própria sociedade, além de ter sua forma de organização expandida para outras ações coletivas, ou seja, um espaço político e de construção da cidadania (CAMARGO; ADRIÃO, 2003).

Assim, o projeto de extensão desenvolvido em parceria com duas escolas públicas dos municípios Jequié - Bahia, enfatizou o fortalecimento dos conselhos escolares, buscando conhecer as ações político-pedagógicas, sociais, administrativas e financeiras desenvolvidas por esses em direção à melhoria da qualidade da educação pública.

Num primeiro contato com as escolas inseridas no projeto, por meio de observações e pesquisa participante, os membros do Grupo puderam estabelecer interações de saberes com os integrantes dos Conselhos Escolares, o que possibilitou observar a atuação desses nas discussões acerca de diversos temas e na promoção de atividades integradas à comunidade. As funções dos Conselhos são relevantes para garantir que os membros da escola e da comunidade apreciem, opinem e proponham ações que contribuam para a solução dos problemas de natureza pedagógica, administrativa ou financeira da escola (CISESKI; ROMÃO, 1997).

Com a continuidade do projeto, as entrevistas com os membros dos Conselhos foram embasadas na leitura das sete dimensões presentes no caderno "Indicadores de Qualidade na Educação" (2004), disponibilizado pelo Ministério da Educação (MEC), a saber: 
ambiente educativo, prática pedagógica, avaliação, gestão democrática escolar, formação e condições dos profissionais de educação, ambiente físico escolar, acesso, permanência e sucesso na escola. Ressaltamos que nessas entrevistas, nem todos os membros foram ouvidos devido a pouca disponibilidade de tempo, bem como o desinteresse por parte de alguns conselheiros.

Os entrevistados relataram que as ações principais desempenhadas pelos Conselhos, estão para garantir uma maior participação dos pais e alunos nas discussões acerca da instituição escolar, preconizando as sugestões desses nas reuniões e projetos desenvolvidos pelas escolas, além de salientarem a preocupação de todos os membros dos Conselhos quanto à aprendizagem dos alunos. Nesse caso, o Conselho deve atuar com função mediadora entre professores e alunos, buscando sempre ressaltar o caráter dialógico do processo educativo em que todos os envolvidos se comprometam a empenhar-se na construção coletiva e significativa do conhecimento. Numa educação emancipadora, que busca a transformação da realidade, o conhecimento passa a ser fruto de uma construção coletiva, e, assim, o professor é mais do que o mero transmissor de conteúdos e o processo de ensino-aprendizagem adquire movimento de troca e de crescimento mútuo (BRASIL, 2004).

É Conveniente acrescentar outra questão referente ao processo de aprendizagem, trata-se da modificação do calendário do conselho de classe, que antes acontecia exclusivamente ao final do ano letivo com alunos que não obtinham um bom resultado na recuperação, sendo organizado, atualmente, ao final das unidades escolares, a fim de discutir a vida escolar dos educandos e seu desempenho durante cada unidade.

A partir dos resultados do trabalho de pesquisa e extensão realizado nas escolas, foi possível organizar uma mesa redonda para debater e compreender o processo de implantação e desenvolvimento dos Conselhos Escolares. Para isso, a colaboração de professores e alunos da UESB, bem como dos Conselheiros Escolares, enriqueceu, 
significadamente, o debate, incentivando a futura promoção de eventos como esse, o qual visa integrar a comunidade acadêmica e a comunidade local na discussão de temas contemporâneos da educação.

O projeto de extensão contribuiu com o fortalecimento dos conselhos escolares das escolas envolvidas, por meio da ressignificação e reflexão da atuação destes como fatores de melhoria na qualidade da educação. Apesar das dificuldades apresentadas, como o pouco envolvimento dos membros dos conselhos e a resistência à cultura política democrática, que envolve tomada coletiva de decisões e corresponsabilidade, os participantes puderam desempenhar as atividades atribuídas ao projeto, evidenciando a necessidade de uma ação continuada no sentido de promover a capacitação e o fortalecimento dos Conselhos Escolares.

Ademais, quanto ao trabalho de estudos, pesquisa e extensão, espera-se abrir novas possibilidades de socialização das experiências realizadas, incentivando outras escolas públicas a implantarem seus conselhos de natureza democrática, contribuindo assim, com a melhoria da educação brasileira.

\section{À guisa de considerações}

Indubitavelmente, a escola deve se constituir como espaço democrático e de participação de todos os envolvidos no processo educativo, fomentando ações coletivas que visem à melhoria da escola pública e, consequentemente, do ensino brasileiro. Reconhecemos que já estamos vivenciando novas práticas de gestão escolar, em que parcerias entre a escola e a comunidade estão sendo concretizadas e é a partir disso que emerge a necessidade de estudarmos e discutirmos os processos de intervenção do Estado nas políticas educacionais e na gestão da escola pública.

Nossos esforços nos permitiram vivenciar os processos democráticos constituídos através das práticas de descentralização do poder, bem como compreender como vem se desenvolvendo a 
democratização administrativo/pedagógica no interior das escolas públicas, enfatizando as perspectivas e desafios em abrir as portas da escola à comunidade, para que ações sejam pensadas e desenvolvidas de forma colaborativa, preconizando a construção de uma nova escola pública em que novos valores éticos e culturais sejam constitutivos de práticas mais democráticas e socialmente referenciadas.

Considerando os seus feitos e perspectivando novas possibilidades, cabe-nos asseverar que o GEPGE consolidou-se como um espaço de discussão, produção e socialização do conhecimento, além de incentivar a participação de novos pesquisadores na área de gestão da escola pública. E é com esse espírito que enfrentaremos desafios que historicamente vem se constituindo em obstáculos à construção de uma sociedade verdadeiramente democrática.

\section{Referências}

BRASIL. Indicadores da qualidade na educação. Unicef, PNUD, Inep-MEC. São Paulo: Ação Educativa, 2004.

. Programa Nacional de Fortalecimento dos Conselhos Escolares. Brasília: SEB/MEC, 2004.

Conselho Escolar e a aprendizagem na escola. Programa Nacional de Fortalecimento dos Conselhos Escolares. Brasília: SEB /MEC, 2004. Disponível em: <http://portal.mec.gov.br>. Acesso: 20 dez. 2010.

CAMARGO, Rubens Barbosa de; ADRIÃO, Theresa Maria de Freitas. Princípios e processos da gestão democrática do ensino: implicações para os Conselhos Escolares. Revista Chão da Escola, Curitiba, n. 2, p. 28-33, 2003. Disponível em: <http://www.upcme.org.br/site/docs/ Rubens\%20Carlos.pdf>. Acesso em: 29 dez .2010.

CISESKI, A. A.; ROMÃO, J. E. Conselhos de escola: coletivos instituintes da escola cidadã. In: GADOTTI, M.; ROMÃO, J. E. (Org.). Autonomia da escola: princípios e propostas. São Paulo: Cortez, 1997. cap. 5, p. 65-74.

GOHN, Maria da Glória. Conselhos gestores e participação sociopolitica. 3. ed. São Paulo: Cortez, 2007. 
LIBÂNEO, José Carlos; OLIVEIRA, João Ferreira de; TOSCHI, Mirza Seabra. Educação escolar: políticas, estrutura e organização. São Paulo: Cortez, 2003.

LIBÂNEO, José Carlos. Organização e gestão da escola: teoria e prática. Goiânia: Alternativa, 2001.

LIMA, Ubirajara Couto. As práticas de participação institucionalizadas e sua relação com a cultura politica: um estudo sobre o conselho de acompanhamento e controle social do FUNDEB. 2009. $109 \mathrm{f}$. Dissertação (Mestrado em Educação) - Programa de Pesquisa e PósGraduação em Educação, Universidade Federal da Bahia, Salvador, 2009.

MENEZES, Raul Miranda. Processo de gasto e descentralização na política educacional brasileira. Em Aberto, Brasília, DF, v. 18, n. 74, 2001.

PARO, Vitor Henrique. Por dentro da escola pública. São Paulo: Xamã, 1995. 